\title{
A Potent Transactivation Domain Mimic With Activity In Living Cells (Supporting Information)
}

\author{
Bo Liu, Prasanna Alluri, Peng Yu and Thomas Kodadek*
}

Departments of Internal Medicine and Molecular Biology and Center for Biomedical Inventions, University of Texas Southwestern Medical Center, 5323 Harry Hines Blvd., Dallas, TX 75390

E-mail: Thomas.Kodadek@utsouthwestern.edu

Chemicals. All reagents and solvents were purchased from Sigma-Aldrich, ACROS, and NOVAbiochem. TentaGel macrobeads (140-170 micron diameter, 0.51 mmole/g capacity) were from Rapp Polymere. Rink Amide MBHA resin (0.69 mmole/g capacity) was from NOVAbiochem.

Peptoid Library Synthesis. 2 g of TentaGel beads was swollen in $N, N$-dimethylformamide (DMF) for 30 minutes. A D-Serine and a Glycine amino acid were added to the beads using standard Fluorenylmethoxy-carbonyl (Fmoc) chemistry on a Rainin 12-channel peptide synthesizer (Protein Technologies). Briefly, the resin was divided into seven equal portions, the Fmoc-group removed with $20 \%$ piperideine in DMF for 10 minutes $(2 \times 2.5 \mathrm{~mL})$ and the beads thoroughly washed with DMF $(8 \times 5$ $\mathrm{mL})$. The beads were then incubated with $2.5 \mathrm{~mL}$ of $0.4 \mathrm{M}$ Fmoc amino acid and $2.5 \mathrm{~mL}$ of $0.4 \mathrm{M}$ HBTU (2-(1H-benzotriazole-1-yl)-1,1,3,3-tetramethyluronium hyxafluorophosphate) in NMP( $N$-methyl-2pyrrolidinone)/DMF for 60 minutes. The beads were thoroughly washed with DMF $(8 \times 5 \mathrm{~mL})$ and the same protocol repeated for coupling the second amino acid. The Fmoc-group on the second amino acid was removed as described previously and the beads were prepared for library synthesis by thoroughly washing them with DMF ( $8 \times 5 \mathrm{~mL})$. The acylation step was carried out in each reaction vessel for 1 hour at $37^{\circ} \mathrm{C}$ using $1.5 \mathrm{~mL}$ each of $2.8 \mathrm{M}$ bromoacetic acid and 3.2 $\mathrm{M}$ diisoprpylcarbodiimide (DIC). After washing the beads thoroughly with DMF $(8 \times 5 \mathrm{~mL})$, a $2 \mathrm{M}$ solution of amine was added and the reaction vessels were shaken at $37^{\circ} \mathrm{C}$ for 90 minutes. All the solutions of the amines were prepared in DMF, except 4-(2-aminoethyl) benzenesulfonamide, which was prepared in dimethylsulphoxide (DMSO). Protection of secondary amino group in tryptamine, one of the primary amino groups in 1,4-diaminobutane and the hydroxyl group ethanolamine was carried out employing previously reported procedures. ${ }^{4,5}$ The beads from all the seven vessels were pooled, randomized by bubbling argon and split again. The protocol was repeated until the desired length was achieved. At the end of the synthesis, the protective groups were removed by treating the beads with a $5 \mathrm{~mL}$ solution of $95 \%$ trifluoroacetic acid (TFA), $2.5 \%$ water and $2.5 \%$ anisole. The beads were then washed thoroughly with dichloromethane, followed by DMF, neutralized with 20\% DIPEA in DMF, rinsed with dichloromethane again, and stored at $4{ }^{\circ} \mathrm{C}$ until further use. Four beads were randomly picked from the library and sequenced by Edman degradation using a previously reported protocol. ${ }^{1}$

Syntheses of Fluorescein Labeled Peptoids (F-KBPo1 and F-KBPo2). Peptoids KBPo1 and KBPo2 were synthesized on Rink Amide MBHA resins using a microwave assisted protocol. ${ }^{2}$ In each synthesis, $36 \mathrm{mg}$ of resins ( $25 \mu$ mole scale) was used. The acylation step was carried out as previously described in $1.0 \mathrm{~mL}$ each of $2 \mathrm{M}$ bromoacetic acid and 3.2M DIC in DMF for 30 seconds. Amine displacement was done in $2 \mathrm{~mL}$ of $2 \mathrm{M}$ amine solution in DMF or DMSO. When the peptoid synthesis

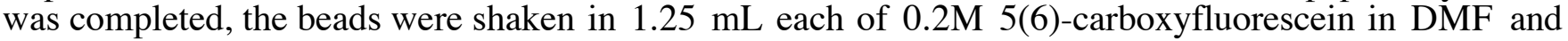
$0.2 \mathrm{M}$ HBTU in NMP/DMF for 60 minutes at room temperature. The beads were washed thoroughly with DMF, dichloromethane, and cleaved in $5 \mathrm{~mL}$ of cleaving cocktail $(95 \%$ TFA, $2.5 \%$ water, and $2.5 \%$ anisole) for $2.5 \mathrm{hr}$. TFA was removed by blowing argon and the products were purified to homogeneity by reverse phase HPLC using a C18 analytical column. F-KBPo1 MALDI-TOF: $[\mathrm{M}+\mathrm{H}]^{+}$calculated 1825.8, found 1825.5. F-KBPo2 MALDI-TOF: $[\mathrm{M}+\mathrm{H}]^{+} \quad$ calculated 1404.5, found 1404.7. 
Syntheses of OxDex-AEEA-KBPo1 and OxDex-AEEA-KBPo2. KBPo1 and KBPo2 were synthesized on Rink AM amide resins at $25 \mu$ mole scale. $N$-(9-Fluorenylmethoxy-carbonyl)-acetylethyleneglycol-ethyl-amine (Fmoc-AEEA-OH) and OxDex-COOH were added to the peptoids using standard Fmoc chemistry. For each coupling step, equal amount (100 $\mu$ mole) of Fmoc-AEEA-OH (or OxDex-COOH), HBTU, HoBt, $32 \mu \mathrm{L}$ of DIPEA, and $14 \mu \mathrm{l}$ of 2,6-lutidine in $2 \mathrm{~mL}$ of anhydrous DMF were applied to the beads. Each coupling step lasted $45 \mathrm{~min}$ at room temperature. The products were cleaved off the beads and purified as described above. OxDex-AEEA-KBPo1 MALDI-TOF: $[\mathrm{M}+\mathrm{H}]^{+}$ calculated 1827.9, found 1827.8. OxDex-AEEA-KBPo2 MALDI-TOF: $[\mathrm{M}+\mathrm{H}]^{+}$calculated 1551.6, found 1550.5 .

Plasmids. E. coli glutathione-S-transferase (GST) expression vector pGEX-2T was purchased from Pharmacia Biotech. E. coli expression vector pGEX-2T-CBP(378-817), ${ }^{3}$ which encodes GST-KIX fusion protein was from Kodadek lab stock. The mammalian cell expression plasmid encoding the Gal4(1-147)-hGRLBD(499-777)-VP16(413-490) fusion, pEDBD-hGRLBD-VP16 was from Kodadek lab stock. Luciferase reporter pG5B was a kind gift from Dr. Marc R. Montminy (Salk Institute). Renilla luciferase expression vector pRL-SV40 was from Promega.

The mammalian cell expression plasmid encoding the Gal4(1-147)-hGRLBD(499-777) fusion was constructed by replacing the reading frame of plasmid pEDBD-hGRLBD-VP16 with Gal4(1-147)hGRLBD(499-777) fusion oligonucleotide. pEDBD-hGRLBD-VP16 was used as a template in a polymerase chain reaction (PCR) with primers PYP007 (5'-CGT CAG ATC CGC TAG CAT GAA GC-3') and PYP008 (5'-CCT GGC GCG GCC GCT CAC TTT TGA TGA AAC AGA AG-3'). The PCR product was purified using Qiaquick PCR purification kit (Qiagen) and was digested with NheI and NotI. The oligonucleotide was inserted in the NheI/NotI cleaved pEDBD-hGRLBD-VP16 vector. The final plasmid was named pEDBD-hGRLBD.

Proteins. GST and GST-KIX proteins were prepared as described. ${ }^{3}$ Texas Red labeled GST-KIX protein was prepared following the same procedure published before. ${ }^{1}$ Bovine serum albumin (BSA) was from PIERCE.

Cell Line. HeLa cells were obtained from the American Type Culture Collection, (CCL-2).

Selection of peptoids against the KIX domain of mouse CREB-binding protein (CBP). Approximately 100,000 beads (190 mg) from the peptoid library were swollen in TBST (50 mM Tris, $\mathrm{pH} 7.4,150 \mathrm{mM} \mathrm{NaCl}, 0.1 \%$ Tween 20) for $1 \mathrm{hr}$. The buffer was removed and the beads were soaked in a prepared $E$. coli lysate at room temperature for $2 \mathrm{hr}$. The $E$. coli lysate was removed and beads were washed with PBS buffer. The beads were then incubated in $5 \mathrm{~mL}$ TBST buffer containing $500 \mathrm{nM}$ Texas Red labeled GST-KIX protein, $25 \mu \mathrm{M}$ GST protein, $0.35 \mathrm{mM}$ (total protein concentration) E.coli cell lysate, and $0.15 \mathrm{mM}$ BSA at room temperature for $1 \mathrm{hr}$. The beads were thoroughly washed with TBST and visualized under a fluorescence microscope. Bright fluorescent beads were picked manually with a micropipette. Each bead was heated in $1 \% \mathrm{SDS}$ at $95{ }^{\circ} \mathrm{C}$ for $5 \mathrm{~min}$ and washed thoroughly with PBS buffer. The sequences of peptoids were solved by single-bead Edman degradation following a previously published protocol. ${ }^{1}$

Fluorescence Polarization Assays. In $200 \mu \mathrm{L}$ of PBS buffer, the indicated amount of proteins (GST-KIX, GST, or BSA), $10 \mu \mathrm{L}$ of BSA ( $2 \mathrm{mg} / \mathrm{mL}$, PIERCE), and approximately $10 \mathrm{nM}$ fluoresceinlabeled peptoids were mixed at room temperature for $20 \mathrm{~min}$. The fluorescence polarization values of samples were measured on a Beacon 2000 fluorescence spectrometer.

Cell Culture, transfection, and luciferase assay. HeLa cells were grown in 24-well plates at $37{ }^{\circ} \mathrm{C}$ under 5\% $\mathrm{CO}_{2}$ in Dulbecco's modified Eagle's medium supplemented with $10 \%$ (v/v) fetal calf serum, $10 \mu \mathrm{g} / \mathrm{mL}$ penicillin, and $10 \mu \mathrm{g} / \mathrm{mL}$ streptomycin. Cells were passed every $24 \mathrm{hr}$ and reached 
$70 \%$ confluence before transfection (about $5 \times 10^{4}$ cells / well). Cells were transfected by the Lipofectamine Plus method (Promega protocol) with $1.01 \mathrm{mg}$ total DNA, including $0.5 \mathrm{mg}$ of pG5B reporter plasmid, $0.5 \mathrm{mg}$ pEDBD-GRLBD ( or pEDBD-GRLBD-VP16), and $10 \mathrm{ng}$ of Renilla luciferase plasmid (pRL-SV40). OxDex-AEEA-KBPo1, OxDex-AEEA-KBPo2, and OxDex-AEEA-CONH ${ }_{2}$ samples at various concentrations were prepared in dimethylsulphoxide (DMSO). After transfection, samples were added directly in the tissue culture media. The DMSO concentration in the media was controlled under $2 \%$. Cells were maintained at $37{ }^{\circ} \mathrm{C}$ under $5 \% \mathrm{CO}_{2}$ with different dosage of chemicals. Luciferase assays were conducted $40 \mathrm{hr}$ after transfection with a dual-luciferase reporter assay system provided by Promega. 5\% of the total cell extract was used in each assay. Luminescence was measured on a Berthold spectrometer (BIOLUMAT LB 9500C). The luminescence from the blank that contains no cell lysate but assay buffer was subtracted from each measured firefly luciferase luminescence. This value was normalized with respect to the Renilla luciferase luminescence. The concentration of a OxDex derivative that results in a half-maximum increase of the induction level is defined as $E C_{50}$. The maximum induction level is defined as $I N D_{\max }$. Induction curve was fitted as

$$
I=\left[C /\left(E C_{50}-C\right)\right] \times\left(I N D_{\max }-1\right)+1
$$

where $I$ is the fold of induction, $C$ is the concentration of the test compound.

\section{Reference}

1. Alluri, P.G., Reddy, M.M., Bachhawat-Sikder, K., Olivos, H.J. \& Kodadek, T. Isolation of protein ligands from large peptoid libraries. J. Am. Chem. Soc. 125, 13995-14004 (2003).

2. Olivos, H.J., Alluri, P.G., Reddy, M.M., Salony, D. \& Kodadek, T. Microwave-assisted solid-phase synthesis of peptoids. Org. Lett. 4, 4057-4059 (2002).

3. Naffin, J.L. et al. Immobilized peptides as high-affinity capture agents for self-associating proteins. Chem Biol. 10, 251-259 (2003).

4. Uno, T., Beausoleil, E., Glodsmith, R. A., Levine, B. H. \& Zuckermann, R. N. Tetrahedron Lett. 40, 1475-1478 (1999).

5. Pons, J.-F., Fauche're, J.-L., Lamaty, F., Molla, A. \& Lazaro, R. Eur. J. Org. Chem. 853-859 (1998). 